\title{
Immunomodulation by thalidomide and thalidomide analogues
}

\author{
Laura G Corral, Gilla Kaplan
}

Tumour necrosis factor $\alpha(\mathrm{TNF} \alpha)$, a key cytokine involved in the host immune response, also contributes to the pathogenesis of both infectious and autoimmune diseases. To ameliorate the pathology resulting from $\mathrm{TNF} \alpha$ in these clinical settings, strategies for the inhibition of this cytokine have been developed. Our previous work has shown that the drug thalidomide is a partial inhibitor of $\mathrm{TNF} \alpha$ production in vivo. For example, when leprosy patients suffering from erythema nodosum leprosum (ENL) are treated with thalidomide, the increased serum $\mathrm{TNF} \alpha$ concentrations characteristic of this syndrome are reduced, with a concomitant improvement in clinical symptoms. Similarly, we have found that in patients with tuberculosis, with or without HIV infection, short-term thalidomide treatment reduces plasma $\mathrm{TNF} \alpha$ levels in association with an accelerated weight gain. In vitro, we have also shown that thalidomide partially inhibits $\mathrm{TNF} \alpha$ produced by human peripheral blood mononuclear cells (PBMC) responding to stimulation with lipopolysaccharide (LPS). Recently, we found that thalidomide can also act as a costimulatory signal for $\mathrm{T}$ cell activation in vitro resulting in increased production of interleukin 2 (IL2) and interferon $\gamma(\mathrm{IFN} \gamma)$. We also observed a bidirectional effect on IL12 production: IL12 production is inhibited by thalidomide when PBMC are stimulated with LPS, however, IL12 production is increased in the presence of the drug when cells are stimulated via the $T$ cell receptor. The latter effect is associated with upregulation of T cell CD40 ligand (CD40L) expression. Thus, in addition to its monocyte inhibitory activity, thalidomide exerts a costimulatory or adjuvant effect on $\mathrm{T}$ cell responses. This combination of effects may contribute to the immunomodulating properties of the drug.

To obtain drugs with increased anti-TNF $\alpha$ activity that have reduced or absent toxicities, novel $\mathrm{TNF} \alpha$ inhibitors were designed using thalidomide as template. These thalidomide analogues were found to be up to 50000 times more active than thalidomide. The compounds comprise two different types of $\mathrm{TNF} \alpha$ inhibitors. One class of compounds, shown to be potent phosphodiesterase 4 (PDE4) inhibitors, are selective $\mathrm{TNF} \alpha$ inhibitors in LPS stimulated PBMC and have either no effect or a suppressive effect on $\mathrm{T}$ cell activation. The other class of compounds also inhibit $\mathrm{TNF} \alpha$ production, but do not inhibit PDE4 enzyme. These compounds are also potent inhibitors of several LPS induced monocyte inflammatory cytokines. Also, the latter compounds markedly stimulate the anti-inflammatory cytokine IL10. Similarly to thalidomide, these drugs that do not inhibit PDE4 act as costimulators of T cells but are much more potent than the parent drug. The distinct immunomodulatory activity of these new $\mathrm{TNF} \alpha$ inhibitors may potentially allow them to be used in the clinic for the treatment of a wide variety of immunopathological disorders of different aetiologies.

\section{TNF $\alpha$ is a key player in the immune response}

$\mathrm{TNF} \alpha$ is a pleiotropic cytokine produced primarily by monocytes and macrophages, but also by lymphocytes and NK cells. TNF $\alpha$ plays a central part in the host immune response to viral, parasitic, fungal and bacterial infections. The importance of $\mathrm{TNF} \alpha$ and $\mathrm{TNF} \alpha$ signalling through its receptors in the host immune response to disease has become clearer as a result of a number of seminal studies. For example, mice genetically deficient in $\mathrm{TNF} \alpha$ have a significantly reduced humoral immune response to adenovirus infection. ${ }^{1}$ In Leishmania major infection, $\mathrm{TNF} \alpha$ signalling is important for protection as mice lacking $\mathrm{TNF} \alpha \mathrm{p} 55$ receptor (TNFR-p55) show delayed elimination of the parasites compared with controls and the lesions formed failed to resolve. ${ }^{2}$ Mice deficient in TNFR-p55 are also significantly impaired in their ability to clear infection with Candida albicans and readily succumb to the infection. TNF $\alpha$ signalling is also crucial in resisting Streptococcus pneumoniae infections in mice. $^{3}$ In addition, $\mathrm{TNF} \alpha$ is essential for protection against murine tuberculosis. TNFR-p55 deficient mice have been shown to be more susceptible to tuberculosis infection. When TNF $\alpha$ was neutralised in vivo by monoclonal antibodies impaired protection against mycobacterial infection was observed. ${ }^{4}$ The data from both models also established that TNF $\alpha$ and the TNFR- p55 are essential for production of reactive nitrogen intermediates by macrophages early in infection.

TNF $\alpha$ contributes to disease pathogenesis Although $\mathrm{TNF} \alpha$ is crucial to the protective immune response, it also plays a part in the pathogenesis of both infectious and autoimmune diseases. Increased concentrations of $\mathrm{TNF} \alpha$ have been shown to trigger the lethal effects of septic shock syndrome. ${ }^{6} \mathrm{TNF} \alpha$ has also been implicated in the development of cachexia, the state of malnutrition that complicates the course of chronic infections and many cancers. ${ }^{7}$ In rheumatoid arthritis, $\mathrm{TNF} \alpha$ is a critical mediator of joint inflammation and therefore an important therapeutic target. 
Recently, it has been shown that treatment of patients with neutralising anti-TNF $\alpha$ antibodies produces a dramatic reduction in disease activity in this condition. ${ }^{8}$ Similarly, it has been shown that in inflammatory bowel disease, neutralisation of $\mathrm{TNF} \alpha$ results in a profound amelioration of clinical symptoms. ${ }^{9}{ }^{10}$ Reductions in $\mathrm{TNF} \alpha$ levels have also been linked with a significant reduction of clinical symptoms in leprosy patients with ENL, including fever, malaise, and arthritic and neuritic pain. ${ }^{11}$ In tuberculosis patients, reduction of $\mathrm{TNF} \alpha$ levels was associated with accelerated weight gain. ${ }^{12}$

\section{Thalidomide inhibits TNF $\alpha$ production by monocytes}

The pathology associated with $\mathrm{TNF} \alpha$ production is profound and in many diseases leads to significant morbidity and mortality. This has led to a concerted effort to discover drugs that will down regulate the production of this cytokine. Agents conventionally used in these diseases may inhibit $\mathrm{TNF} \alpha$ production, but are also often broadly immunosuppressive (for example, cyclosporin A and corticosteroids) and therefore associated with extensive side effects. ${ }^{13}$ Drugs that are potentially more specific in inhibiting $\mathrm{TNF} \alpha$ are under active investigation and development. Our previous work has shown that the drug thalidomide $(\alpha-\mathrm{N}$-phthalimidiglutarimide) is a relatively selective inhibitor of $\mathrm{TNF} \alpha$ production by human monocytes in vivo. This property of thalidomide was first described in leprosy patients with ENL, an acute inflammatory complication of lepromatous leprosy that is accompanied by increased serum $\mathrm{TNF} \alpha$ levels. Thalidomide treatment of patients with ENL was shown to induce a prompt reduction of $\mathrm{TNF} \alpha$ serum levels with a concomitant abrogation of clinical symptoms. ${ }^{11}$ Furthermore, in patients with tuberculosis, with or without concomitant HIV infection, thalidomide treatment was found to both decrease plasma $\mathrm{TNF} \alpha$ protein levels as well as monocyte $\mathrm{TNF} \alpha \mathrm{mRNA}$ levels. This decrease was associated with an accelerated weight gain. ${ }^{12}$ In a rabbit model of mycobacterial meningitis, thalidomide treatment combined with antibiotics produced a marked reduction in $\mathrm{TNF} \alpha$ levels, leucocytosis, and brain disease. ${ }^{14}$ In addition, thalidomide inhibited $\mathrm{TNF} \alpha$ serum levels in mice challenged with LPS thus partially protecting the animals from septic shock. ${ }^{15}$

In vitro, we have found that thalidomide selectively reduces the production of TNF $\alpha$ by human monocytes cultured in the presence of both LPS and mycobacterial products. ${ }^{16}$ However, this inhibition was only partial $(50 \%$ to $70 \%$ ) possibly because of the instability of the drug in aqueous solutions. ${ }^{17}$ The mechanism by which thalidomide reduces $\mathrm{TNF} \alpha$ production is still unclear. The drug seems to inhibit $\mathrm{TNF} \alpha$ production by human monocytes in vitro in association with enhanced degradation of TNF $\alpha$ mRNA. ${ }^{18}$ It also inhibits the activation of the nuclear factor $\kappa \mathrm{B}(\mathrm{Nf} \kappa \mathrm{B}),{ }^{19}{ }^{20}$ a promoter for the transcription of TNF $\alpha$ as well as transcription of HIV-1. ${ }^{21} 22$

\section{Thalidomide has $\mathbf{T}$ cell costimulatory} properties

Recently, we reported that thalidomide also has a hitherto unappreciated immunomodulatory effect: the drug was shown to costimulate human $T$ cells in vitro, synergising with stimulation via the $T$ cell receptor complex to increase IL 2 mediated $\mathrm{T}$ cell proliferation and $\mathrm{T}$ cell IFN $\gamma$ production. ${ }^{23}$ Optimal $\mathrm{T}$ cell activation requires two signals. ${ }^{24}$ The first signal or signal 1 is delivered by clustering of the $\mathrm{T}$ cell antigen-receptor-CD3 complex through engagement of specific foreign peptides bound to MHC molecules on the surface of an antigen presenting cell (APC). Signal 1 can be mimicked by crosslinking the $\mathrm{T}$ cell receptor (TCR) complexes with anti-CD3 antibodies. Signal 2 (or costimulation) is antigen independent and may be provided by cytokines or by surface ligands on the APC that interact with their receptors on the $\mathrm{T}$ cell. Costimulatory signals are essential to induce maximal $\mathrm{T}$ cell proliferation and secretion of cytokines, including IL2, which ultimately drive $\mathrm{T}$ cell clonal expansion. As antigenic stimulation in the absence of costimulatory signals leads to $\mathrm{T}$ cell anergy or apoptosis, costimulation is critically important in the induction and regulation of cellular immunity.

Thalidomide appears to act as a costimulator to $T$ cells that have received signal 1 via the TCR..$^{23}$ In our experiments in vitro, stimulation of purified $\mathrm{T}$ cells with anti-CD3 antibodies, in the absence of signal 2 , induced only minimal $\mathrm{T}$ cell proliferation. However, the addition of thalidomide to this cell culture system resulted in a concentration dependent increase in proliferative responses. ${ }^{23} 25$ The thalidomide mediated costimulation of $\mathrm{T}$ cell proliferation was accompanied by increases in IL 2 and IFN $\gamma$ production. It is noteworthy that in the absence of anti-CD3, there was no $\mathrm{T}$ cell proliferative response to thalidomide, indicating that the drug is not mitogenic in itself. It is also interesting to note that in these experiments, thalidomide did not inhibit $\mathrm{TNF} \alpha$ production by purified $\mathrm{T}$ cells stimulated by anti-CD3 antibodies. This is in contrast with the effects of the drug on $\mathrm{TNF} \alpha$ produced by monocytes. As already described above, thalidomide inhibits monocyte $\mathrm{TNF} \alpha$ production. The costimulatory effect of thalidomide was greater on the $\mathrm{CD} 8+\mathrm{T}$ cells than on the CD4+ $\mathrm{T}$ cell subset. ${ }^{23}$

In addition to its effects on $\mathrm{T}$ cell proliferation and $\mathrm{T}$ cell cytokine production, we observed that thalidomide induced the upregulation of CD40L expression on activated T cells. $^{25}{ }^{26} \mathrm{CD} 40 \mathrm{~L} / \mathrm{CD} 40$ interaction occurs early in the sequence of signalling events between $T$ cells and antigen presenting cells (APC). Signalling through CD40 has been shown to activate APC and to induce expression of costimulatory molecules such as B7, as well as stimulating production of IL12. ${ }^{27}$ Thus, CD40 signalling results in a stimulatory feedback mechanism in which the activated APC amplifies the T cell response. ${ }^{29}$ It has also been suggested that CD40L function is essen- 
tial for the survival of CD8 $+\mathrm{T}$ cells and that in its absence these cells die or become anergic. ${ }^{30}$

These studies show that in addition to its inhibitory effect on the production of monocyte cytokines, thalidomide exerts a costimulatory or adjuvant effect on $\mathrm{T}$ cell responses. The immune modulating effects of the drug in patients may thus be attributable to a balance between the inhibition of production of monocyte cytokines, including $\mathrm{TNF} \alpha$, and the costimulation of $\mathrm{T}$ cell activity. The effects of thalidomide in vivo in HIV infected patients seem to reflect the costimulatory activity of the drug. ${ }^{26}$ In a placebo controlled study to evaluate the effects of in vivo immunomodulation with thalidomide, the drug was administered for four weeks to HIV infected patients. Thalidomide treatment did not affect $\mathrm{TNF} \alpha$ levels in these patients. In contrast, thalidomide treatment resulted in significant immune stimulation. This was reflected by increases in DTH responses and increased plasma levels of $\mathrm{T}$ cell activation markers such as soluble IL2 receptor (sIL2R) and soluble CD8 antigen. An earlier study of tuberculosis patients treated with thalidomide showed increased plasma levels of IFN $\gamma$ suggesting an immunostimulatory effect of the drug. ${ }^{12}$ Recently, patients suffering from sarcoidosis have shown consistent increases in sIL2R plasma levels after thalidomide treatment (Oliver et al, manuscript in preparation). In the same study, thalidomide treatment increased the proliferation of sarcoid patient $\mathrm{T}$ cells in response to concanavalin $\mathrm{A}$ in vitro. These results strongly suggest that thalidomide directly stimulates $\mathrm{T}$ cells in vivo in patients, corresponding to the $\mathrm{T}$ cell costimulatory properties of the drug observed in vitro in $\mathrm{T}$ cells from normal donors, ${ }^{23}{ }^{25}$ as well as in the T cells of HIV infected patients. ${ }^{26}$

\section{Thalidomide analogues are improved TNF $\alpha$ inhibitors}

In addition to being the drug of choice for the treatment of ENL, thalidomide has been shown to be useful in a number of clinical situations including rheumatoid arthritis, HIV associated aphthous ulcers and chronic graft versus host disease. ${ }^{31-34}$ However, thalidomide is a potent teratogen and ingestion of the drug by a pregnant woman can lead to catastrophic

Thalidomide

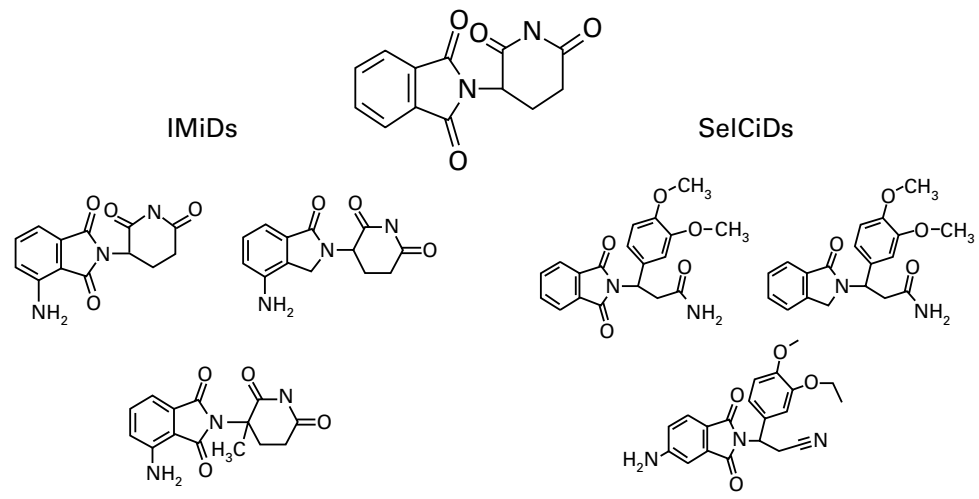

Figure 1 Chemical structures of thalidomide and selected thalidomide analogues. birth defects. ${ }^{35}$ In addition, thalidomide treatment is often accompanied by a number of side effects, including peripheral neuropathy. ${ }^{36}$ Therefore, the use of thalidomide requires strict monitoring of all patients. ${ }^{37}$ Thus, there is a pressing need to develop drugs with increased $\mathrm{TNF} \alpha$ inhibitory activity and reduced or absent toxicities. Towards this end, structural analogues of thalidomide have been designed and synthesised at Celgene Corporation (Warren, New Jersey) and screened for inhibition of $\mathrm{TNF} \alpha$ production. A large number of potent novel $\mathrm{TNF} \alpha$ inhibitors were thus identified. Recently, some of these compounds were described. ${ }^{20}{ }^{38-40}$ On a molar basis, the more potent of these thalidomide analogues were found to be up to 50000 -fold more potent than thalidomide at inhibiting $\mathrm{TNF} \alpha$ production by human PBMC stimulated by LPS in vitro. Furthermore, we have shown that some of these compounds retain high activity in LPS stimulated human whole blood. ${ }^{40}$ In vivo, several of these new compounds showed improved activity in reducing LPS induced $\mathrm{TNF} \alpha$ levels in mice ${ }^{17}$ and in inhibiting the development of adjuvant arthritis in rats. ${ }^{40 a}$

\section{Thalidomide analogues comprise two distinct classes of molecules}

A group of thalidomide analogues, selected for their capacity to potently inhibit $\mathrm{TNF} \alpha$ production by LPS stimulated PBMC, was further investigated (fig 1). When tested for their effect in vitro on LPS induced cytokines, different patterns of cytokine modulation were shown. ${ }^{25}$ One class of compounds, class I or ImiDs (Immunomodulatory Imide Drugs) showed not only potent inhibition of TNF $\alpha$ but also marked inhibition of LPS induced monocyte IL1 $\beta$ and IL1 2 production. LPS induced IL6 was also inhibited by these drugs, albeit partially. These drugs were potent stimulators of LPS induced IL10, increasing IL10 levels by $200-300 \%$. In contrast, the other class of compounds, class II or SelCiDs (Selective Cytokine Inhibitory Drugs), while still potently inhibiting $\mathrm{TNF} \alpha$ production, had a more modest inhibitory effect on LPS induced IL1 $\beta$ and IL12, and did not inhibit IL6 even at high drug concentrations. In addition, SelCiDs produced a more modest IL10 stimulation (20-50\% increases). In all of these characteristics, SelCiDs were more similar to thalidomide than ImiDs. ${ }^{16} 17$

Further characterisation of the SelCiDs showed that they are potent PDE4 inhibitors. ${ }^{39}$ PDE4 is one of the major phosphodiesterase isoenzymes found in human myeloid and lymphoid lineage cells. ${ }^{41}$ The enzyme plays a crucial part in regulating cellular activity by degrading the ubiquitous second messenger cAMP and maintaining it at low intracellular levels. Inhibition of PDE4 results in increased cAMP levels leading to the modulation of LPS induced cytokines including inhibition of $\mathrm{TNF}^{4}{ }^{42}$ Increasing intracellular cAMP levels have been shown to inhibit $\mathrm{TNF} \alpha$ production in monocytes as well as in lymphocytes, ${ }^{41}{ }^{43}$ although it is not clear how this inhibition is 
regulated. Interestingly, the IMiDs and thalidomide were found not to inhibit PDE4. ${ }^{40}$

In addition to the differential modulation of LPS induced monocyte cytokines, the two classes of compounds showed distinct effects on $\mathrm{T}$ cell activation. SelCiDs, the PDE4 inhibitors, had little effect on $\mathrm{T}$ cell activation causing only a slight inhibition of $\mathrm{T}$ cell proliferation. This effect was not unexpected as it is well established that increasing cAMP levels in $\mathrm{T}$ cells during the early phase of mitogen or antigen activation results in a decrease in proliferative potential. ${ }^{44}$ On the other hand, IMiDs, the non-PDE4 inhibitors, were potent costimulators of $\mathrm{T}$ cells and increased cell proliferation dramatically in a dose dependent manner. ${ }^{25}$ Similarly to thalidomide, these compounds had a greater costimulatory effect on the CD8+ T cell subset than on the CD4+ T cell subset (Corral et al, unpublished observation). IMiDs, when added to anti-CD3 stimulated $\mathrm{T}$ cells, also caused marked increases in the secretion of IL 2 and IFN $\gamma$ and induced the up-regulation of CD40L expression on $\mathrm{T}$ cells. ${ }^{25}$ These findings show that in addition to their strong anti-inflammatory properties, IMiDs efficiently costimulate T cells with 100 to 1000 times the potency of the parent drug. The molecular target of these co-stimulatory cytokine modulating drugs is as yet unknown.

\section{Thalidomide and IMiDs modulate cytokines differently according to cell type and stimulation pathway}

As described above, thalidomide has been shown to inhibit IL12 production by LPS stimulated monocytes in vitro..$^{25}$ In vivo, however, thalidomide treatment of HIV infected $^{26}$ and $M$ tuberculosis infected patients induced increases in plasma IL12 levels (Bekker et al, submitted data). Thalidomide treatment also resulted in increases in plasma IL12 levels in patients with scleroderma and sarcoidosis (Oliver et al, manuscripts in preparation). These dual and opposite effects of thalidomide may be explained by the differential modulation of cytokines according to target cell type and specific pathways of cellular stimulation.

IL12 is produced primarily by APC (monocytes/macrophages and dendritic cells) and is regulated by both $\mathrm{T}$ cell dependent and $\mathrm{T}$ cell independent pathways. LPS directly induces $\mathrm{T}$ cell independent IL12 production by APC, which is inhibited by thalidomide. In the $\mathrm{T}$ cell dependent pathway, on the other hand, the production of IL12 by the APC is induced primarily by the interaction of CD40 on the surface of the APC with CD40L on the surface of activated T cells. ${ }^{28}{ }^{46}$ When $\mathrm{T}$ cells were stimulated by anti-CD3, thalidomide and IMiDs treatment caused a significant stimulation of IL12 production. ${ }^{25}$ Thalidomide and IMiDs also induced an up-regulation of CD40L on the surface of T cells. ${ }^{25}{ }^{26}$ Blockade of this pathway inhibits the production of IL12 and abolishes the stimulatory effect of thalidomide. ${ }^{26}$ Interestingly, in HIV infected patients, the consistent increases in plasma IL12 levels induced by thalidomide treatment lagged behind the increases in $\mathrm{T}$ cell activation markers. ${ }^{26}$ This observation suggested that IL12 production was augmented as a consequence of drug induced $\mathrm{T}$ cell activation.

The dichotomous nature of thalidomide cytokine modulation may explain the seemingly opposite effects observed in different clinical situations. When patients with Behçet's syndrome are treated with thalidomide, healing of inflammatory aphthous ulcers occurs, but is sometimes accompanied by exacerbation of erythema nodosum. ${ }^{47}$ Similarly, the paradoxical worsening of graft versus host disease ${ }^{48}$ and toxic epidermal necrolysis ${ }^{49}$ reported in clinical trials of thalidomide may be a manifestation of the unsuspected immune stimulatory effect of this drug.

\section{Potential clinical applications of thalidomide and thalidomide analogues} The thalidomide analogues discussed here seem to have retained different properties of the parent drug (table 1). The distinct immunomodulatory activities of these two classes of drugs suggest they may have applications in different immunopathological disorders. SelCiDs, which inhibit PDE4, may be used in clinical situations in which PDE4 inhibition and selective $\mathrm{TNF} \alpha$ inhibition are beneficial. Therapeutic increase of intracellular cAMP levels by PDE4 inhibitors has antiinflammatory effects, which may afford consequent benefits in a variety of diseases such as asthma, ${ }^{50}$ atopic dermatitis ${ }^{51}$ and rheumatoid arthritis. ${ }^{52}$ Indeed, in an animal model of adjuvant arthritis, thalidomide derived PDE4 inhibitors have shown efficacy in suppressing the development of disease as measured by ankle swelling, hind limb radiographic changes and weight gain. ${ }^{40 a}$ The suppression of arthritis was accompanied by a reduction in $\mathrm{TNF} \alpha$ and IL2 mRNA levels in the ankle joints of treated rats.

Table 1 Immunomodulatory profiles of thalidomide and thalidomide analogues

\begin{tabular}{lll}
\hline Thalidomide & IMiDs & SelCIDs \\
\hline $\begin{array}{c}\text { Inhibits LPS induced inflammatory } \\
\text { cytokines TNF } \alpha \text { and IL12 }\end{array}$ & $\begin{array}{c}\text { Strongly inhibit LPS induced inflammatory } \\
\text { cytokines: TNF } \text {, IL1 } \beta \text {, IL6 and IL12 }\end{array}$ & $\begin{array}{c}\text { Strongly inhibit LPS induced } \\
\text { inflammatory cytokines TNF } \alpha \text { and IL12 }\end{array}$ \\
$\begin{array}{c}\text { Stimulates LPS induced } \\
\text { anti-inflammatory cytokine IL10 }\end{array}$ & $\begin{array}{c}\text { Strongly stimulate LPS induced } \\
\text { anti-inflammatory cytokine IL10 }\end{array}$ & $\begin{array}{c}\text { Stimulate LPS induced } \\
\text { anti-inflammatory cytokine IL10 } \\
\text { Costimulates T cell activation }\end{array}$ \\
Strongly costimulate T cell activation & $\begin{array}{c}\text { Inhibit or have no effect on T cell } \\
\text { activation }\end{array}$ \\
Does not inhibit PDE4 & Do not inhibit PDE4 & Strongly inhibit PDE4 \\
\hline
\end{tabular}


Other known selective PDE4 inhibitors, such as rolipram, have been reported to have dose limiting side effects, such as nausea and vomiting, which limit the therapeutic use of these drugs. ${ }^{53}{ }^{54}$ These side effects may be produced by the lack of specificity of these drugs - that is, the compounds inhibit one or more PDE isoenzymes in non-target tissues. For example, it is probable that the emetic activity of PDE4 inhibitors is attributable to an action of the drugs in the CNS. ${ }^{55}$ Intensive effort is being directed towards identifying compounds with improved therapeutic ratios. Preliminary results with thalidomide derived PDE inhibitors indicate that these novel drugs are selective inhibitors of PDE4 and may be better tolerated than other PDE4 inhibitors, as they have not shown evidence of emesis in animals. One of these drugs has been recently shown to be well tolerated in a small human safety trial in the United Kingdom (D Stirling, personal communication).

The IMiDs, as thalidomide, are antiinflammatory drugs that do not target PDE4. These compounds, in addition to their potential use to decrease inflammation, could also be useful in clinical settings where there is a defect in $\mathrm{T}$ cell function, as in HIV disease. HIV infection is accompanied by deficiencies in the production of IL12 and in the up-regulation of CD40L. ${ }^{5657}$ IL12 has been shown to restore HIV specific cell mediated immunity in vitro ${ }^{58}$ and to increase HIV specific CTL responses in vitro $^{59}$ and in vivo. ${ }^{60}$ Also, deficient IL12 responses in HIV infected patients can be restored in vitro by $\mathrm{CD} 40 \mathrm{~L}$ and $\mathrm{IFN} \gamma,{ }^{61}$ the same costimulatory factors induced by thalidomide and IMiDs. Thus, these drugs may eventually be used to restore or stimulate IL12 production in immune deficient patients.

IL12 has also been shown to exhibit potent anti-tumour activity in murine tumour models through various mechanisms including the stimulation of natural killer cell activity, ${ }^{62}$ activation of CD8+ cytotoxic T cells ${ }^{63}$ and increased IFN $\gamma$ mediated anti-angiogenesis. ${ }^{64}$ Thalidomide has also recently been reported to exhibit anti-tumour activity through the inhibition of angiogenesis in vivo. ${ }^{65-68}$ However, this antiangiogenic effect does not seem to be mediated by $\mathrm{TNF} \alpha$ inhibition. Although these studies did not determine the mechanism of thalidomide's anti-angiogenic activity, it is conceivable that stimulation of IFN $\gamma / \mathrm{IL} 12$ levels may be at least partly responsible. One report indicates that thalidomide may have anti-angiogenic activity in multiple myeloma in humans. ${ }^{69}$

In summary, our recent findings that thalidomide and IMiDs preferentially costimulate $\mathrm{CD} 8+\mathrm{T}$ cells and induce $\mathrm{T}$ cell dependent IL12 production suggest possible applications of these drugs in the control of viral infections ${ }^{70} 71$ or in boosting anti-tumour immunity ${ }^{72}{ }^{73}$ Also, there are anecdotal reports of the efficacy of thalidomide in treating refractory inflammatory bowel disease. ${ }^{74-76}$ Recently, preliminary findings were announced from a pilot study with patients with Crohn's disease refractory to standard treatments (Annual Digestive Disease Meeting, May 1999, Or- lando, FL). In this study, two third of the patients experienced a significant improvement in their condition. This therapeutic effect may be a combination of $\mathrm{TNF} \alpha$ inhibition and CD8+ T cell stimulation. ${ }^{77} 78$

\section{Conclusions}

In several disease conditions such as septic shock, chronic infections and cancer, overproduction of $\mathrm{TNF} \alpha$ is accompanied by severe toxicities. Thalidomide inhibits $\mathrm{TNF} \alpha$ production in different diseases without causing the immunosuppression often associated with standard agents such as glucocorticoids and cyclosporin A. Our results indicate that the immunomodulating effects of thalidomide may occur via the inhibition of $\mathrm{TNF} \alpha$ production and/or the stimulation of $\mathrm{T}$ cell responses, without the suppression of host immunity.

Recent efforts have concentrated on developing $\mathrm{TNF} \alpha$ inhibitors that are efficient, safe and specific. The collaboration between Rockefeller University and Celgene Corporation scientists has led to the discovery of two different classes of immunomodulators derived from thalidomide and selected for their potent anti-TNF $\alpha$ inhibitory activity. Preliminary results indicate that at least some of these new compounds are non-toxic and non-teratogenic. ${ }^{20}$ The two classes of thalidomide analogues, however, possess distinct properties. IMiDs are potent inhibitors of monocyte inflammatory cytokine production and also are strong costimulators of $\mathrm{T}$ cell activity. SelCiDs, on the other hand, are potent PDE4 inhibitors and thus, more selective inhibitors of TNF $\alpha$. Unlike IMiDs, these compounds do not costimulate $\mathrm{T}$ cells but inhibit $\mathrm{T}$ cell activity. Thus, the two classes of compounds may prove to be useful in different clinical settings according to their immunomodulatory properties. The thalidomide analogues are being used as investigational tools in animal disease models to define mechanisms of pathogenesis and to continue to elucidate the mechanisms of drug action.

We thank Dr Victoria Freedman and Dr George Muller for helpful and patient review of this manuscript, Marguerite Nulty for typing the manuscript and Dr Patrick Haslett for critical discussions during the preparation of this report.

1 Elkon K. Tumor necrosis factor alpha plays a central role in immune-mediated clearance of adenoviral vectors. Proc Natl Acad Sci USA 1997;94:9814-19.

2 Nashleanas M, Kanaly S, Scott P. Control of Leishmania major infection in mice lacking TNF receptors. J Immunol 1998;160:5506-13

3 O'Brien D. Tumor necrosis factor alpha receptor I is important for survival from Streptococcus pneumoniae infections. Infect Immun 1999;67:595-601.

4 Flynn JL, Goldstein MM, Chan J, et al. Tumor necrosis factor-alpha is required in the protective immune response against Mycobacterium tuberculosis in mice. Immunity 1995;2:561-72

5 Kindler V, Sappino AP, Grau GE, Piguet PF, Vassalli P. The inducing role of tumor necrosis factor in the development of bactericidal granulomas during BCG infection. Cell 1989;56:731-40.

6 Waage A, Steinshamn S. Cytokine mediators of septic infections in the normal and granulocytopenic host. Eur J Haematol 1993;50:243-9.

7 Tracey KJ, Cerami A. Tumor necrosis factor and regulation of metabolism in infection: role of systemic versus tissue levels. Proc Soc Exp Biol Med 1992;200:233-9.

8 Maini RN, Elliott MJ, Brennan FM, Feldmann M. Meneficial effects of tumour necrosis factor-alpha (TNFBeneficial effects of tumour necrosis factor-alpha (TNF-
alpha) blockade in rheumatoid arthritis (RA) [published erratum appears in Clin Exp Immunol 1995;102:443]. Clin Exp Immunol 1995;101:207-12. 
9 Hawkey CJ, Stack WA. Chimeric monoclonal antibody cA2 to tumor necrosis factor alpha for Crohn's disease [letter] 8;338:333-4.

10 Baert FJ, D'Haens GR, Peeters M, et al. Tumor necrosis factor alpha antibody (infliximab) therapy profoundly down-regulates the inflammation in Crohn's ileocolitis. Gastroenterology 1999;116:22-8.

11 Sampaio EP, Kaplan G, Miranda A, et al. The influence of thalidomide on the clinical and immunologic manifestation of erythema nodosum leprosum. J Infect Dis 1993;168: 408-14.

12 Tramontana JM, Utaipat U, Molloy A, et al. Thalidomide treatment reduces tumor necrosis factor alpha production and enhances weight gain in patients with pulmonary tuberculosis. Mol Med 1995;1:384-97.

13 Fenner H. [TNF inhibitors: a new therapeutic perspective in chronic inflammatory diseases in rheumatology?]. Z Rheumatol 1995;54:158-64.

14 Tsenova L, Sokol K, Freedman VH, Kaplan G. A combination of thalidomide plus antibiotics protects rabbits from mycobacterial meningitis-associated death. J Infect Dis mycobacterial mening

15 Moreira AL, Wang J, Sarno EN, Kaplan G. Thalidomide protects mice against LPS-induced shock. Braz J Med Bio Res 1997;30:1199-207.

16 Sampaio EP, Sarno EN, Galilly R, Cohn ZA, Kaplan G. Thalidomide selectively inhibits tumor necrosis factor alpha production by stimulated human monocytes. J Exp Med 1991;173:699-703.

17 Corral LG, Muller GW, Moreira AL, et al. Selection of novel analogs of thalidomide with enhanced tumor necrosis factor alpha inhibitory activity. Mol Med 1996;2:506-15.

18 Moreira AL, Sampaio EP, Zmuidzinas A, Frindt P, Smith KA, Kaplan G. Thalidomide exerts its inhibitory action on tumor necrosis factor alpha by enhancing mRNA degradatumor necrosis factor alpha by enhan

19 Moreira AL, Corral LG, Ye W, et al. Thalidomide and thalidomide analogs reduce HIV type 1 replication in human macrophages in vitro. AIDS Res Hum Retroviruses $1997 ; 13: 857-63$

20 Marriott JB, Westby M, Cookson S, et al. CC-3052: a watersoluble analog of thalidomide and potent inhibitor of activation-induced TNF-alpha production. J Immunol 1998;161:4236-43

21 Muller JM, Ziegler-Heitbrock HW, Baeuerle PA. Nuclear factor kappa B, a mediator of lipopolysaccharide effects. Immunobiology 1993;187:233-56.

22 Bachelerie F, Alcami J, Arenzana-Seisdedos F, Virelizier JL. HIV enhancer activity perpetuated by NF-kappa B induc-
tion on infection of monocytes. Nature 1991;350:709-12.

23 Haslett PA, Corral LG, Albert M, Kaplan G. Thalidomide costimulates primary human $\mathrm{T}$ lymphocytes, preferentially inducing proliferation, cytokine production, and cytotoxic
responses in the CD8+ subset. J Exp Med 1998;187:188592.

24 Mueller DL, Jenkins MK, Schwartz RH. Clonal expansion versus functional clonal inactivation: a costimulatory signalling pathway determines the outcome of $\mathrm{T}$ cel antigen receptor occupancy. Annu Rev Immunol 1989;7 445-80.

25 Corral LG, Haslett PAJ, Muller GW, et al. Differential cytokine modulation and $\mathrm{T}$ cell activation by two distinct classes of thalidomide analogs which are potent inhibitors of TNF-alpha. J Immunol 1999;163:380-6.

26 Haslett PAJ, Klausner JD, Makonkawkeyoon S, et al. Thalidomide stimulates $\mathrm{T}$ cell responses and interleukin-12 production in HIV-infected patients. AIDS Res Hum Retroviruses 1999;15:1169-79.

27 Ranheim EA, Kipps TJ. Activated T cells induce expression of $\mathrm{B} 7 / \mathrm{BB} 1$ on normal or leukemic B cells through a CD40of B7/BB1 on normal or leukemic B cells through
dependent signal. J Exp Med 1993;177:925-35.

28 DeKruyff RH, Gieni RS, Umetsu DT Antigen-driven but not lipopolysaccharide-driven IL-12 production in macrophages requires triggering of CD40. J Immunol 1997;158: 359-66.

29 Hollenbaugh D, Ochs HD, Noelle RJ, Ledbetter JA, Aruffo A. The role of CD40 and its ligand in the regulation of the immune response. Immunol Rev 1994;138:23-37.

30 Buhlmann JE, Gonzalez M, Ginther B, et al. Cutting edge: sustained expansion of CD8+ T cells requires CD154 expression by Th cells in acute graft versus host disease. J Immunol 1999; 162:4373-6.

31 Klausner JD, Makonkawkeyoon S, Akarasewi P, et al. The effect of thalidomide on the pathogenesis of human immunodeficiency virus type 1 and $M$. tuberculosis infection. J Acquir Immune Defic Syndr Hum Retrovirol 1996;11: Acquir

32 Schuler U, Ehninger G. Thalidomide: rationale for renewed use in immunological disorders. Drug Saf 1995;12:364-9.

33 Jacobson JM, Greenspan JS, Spritzler J, et al. Thalidomide for the treatment of oral aphthous ulcers in patients with human immunodeficiency virus infection. National Institute of Allergy and Infectious Diseases AIDS Clinical Trials

34 Vogelsang GB, Farmer ER, Hess AD, et al. Thalidomide for the treatment of chronic graft-versus-host disease [see comments]. N Engl J Med 1992;326:1055-8.

35 Castilla EE, Ashton-Prolla P, Barreda-Mejia E, et al. Thalidomide, a current teratogen in South America. Teratology 1996;54:273-7.

36 Tseng S, Pak G, Washenik K, Pomeranz MK, Shupack JL. Rediscovering thalidomide: a review of its mechanism of action, side effects, and potential uses. J Am Acad Dermatol 1996;35:969-79.
37 Gunzler V. Thalidomide in human immunodeficiency virus HIV) patients. A review of safety considerations. Drug Saf 992;7:116-34.

38 Muller GW, Corral LG, Shire MG, et al. Structural modifications of thalidomide produce analogs with enhanced tumor necrosis factor inhibitory activity. J Med Chem 1996;39:3238-40

39 Muller GW, Shire MG, Wong LM, et al. Thalidomide analogs and PDE4 inhibition. Bioorg Med Chem Lett 1998;8: 2669-74.

40 Muller GW, Chen R, Huang S-Y, et al. Amino-substituted thalidomide analogs: potent inhibitors of TNF-alpha production. Bioorg Med Chem Lett 1999;9:1625-30.

40a Oliver SJ, Freeman SL, Corral LG, Ocampo C, Kaplan G. Thalidomide analog CC1069 inhibits development of rat adjuvant arthritis. Clin Exp Immunol (in press).

41 Verghese MW, McConnell RT, Lenhard JM, Hamacher L, Jin SL. Regulation of distinct cyclic AMP-specific phosphodiesterase (phosphodiesterase type 4) isozymes in
human monocytic cells. Mol Pharmacol 1995;47:1164-71.

42 Verghese MW, McConnell RT, Strickland AB, et al. Differential regulation of human monocyte-derived TNF alpha (cAMP-PDE) inhibitors. J Pharmacol Exp Ther 1995;272: 1313-20.

43 Gantner F, Kusters S, Wendel A, Hatzelmann A, Schudt C, Tiegs G. Protection from T cell-mediated murine liver failure by phosphodiesterase inhibitors. J Pharmacol Exp Ther 1997; $280: 53-60$

44 Tamir A, Granot Y, Isakov N. Inhibition of T lymphocyte activation by cAMP is associated with down- regulation of two parallel mitogen-activated protein kinase pathways, the extracellular signal-related kinase and c-Jun N-terminal kinase. J Immunol 1996;157:1514-22.

45 Moller DR, Wysocka M, Greenlee BM, et al. Inhibition of IL-12 production by thalidomide. J Immunol 1997;159: 5157-61.

46 Takenaka H, Maruo S, Yamamoto N, et al. Regulation of T cell-dependent and -independent IL-12 production by the three Th2-type cytokines IL-10, IL-6, and IL-4. J Leukoc Biol 1997;61:80-7.

47 Hamuryudan V, Mat C, Saip S, et al. Thalidomide in the treatment of the mucocutaneous lesions of the Behcet syndrome. A randomized, double-blind, placebo-controlled trial. Ann Intern Med 1998;128:443-50.

48 Chao NJ, Parker PM, Niland JC, et al. Paradoxical effect of thalidomide prophylaxis on chronic graft-vs.-host disease. Biol Blood Marrow Transplant 1996;2:86-92.

49 Wolkenstein P, Latarjet J, Roujeau JC, et al. Randomised comparison of thalidomide versus placebo in toxic epidermal necrolysis. Lancet 1998;352:1586-9.

50 Harbinson PL, MacLeod D, Hawksworth R, et al. The effect of a novel orally active selective PDE4 isoenzyme inhibitor (CDP840) on allergen-induced responses in asthmatic subjects. Eur Respir J 1997;10:1008-14.

51 Hanifin JM, Chan SC, Cheng JB, et al. Type 4 phosphodiesterase inhibitors have clinical and in vitro anti- inflammatory effects in atopic dermatitis. J Invest Dermatol 1996;107:51-6.

52 Sekut L, Yarnall D, Stimpson SA, et al. Anti-inflammatory activity of phosphodiesterase (PDE)-IV inhibitors in acute and chronic models of inflammation. Clin Exp Immunol 1995;100:126-32.

53 De Brito FB, Souness JE, Warne PJ. Type 4 phosphodiesterase inhibitors and their potential in the treatment of inflammatory disease. Emerging Drugs 1997;2:247-68.

54 Torphy TJ. Phosphodiesterase Isozymes: molecular targets for novel antiasthma agents. Am J Respir Crit Care 1998;157:351-70.

55 Carpenter DO, Briggs DB, Knox AP, Strominger N. Excitation of area postrema neurons by transmitters, peptides, and cyclic nucleotides. J Neurophysiol 1988;59:358-69.

56 Chirmule N, McCloskey TW, Hu R, Kalyanaraman VS, Pahwa S. HIV gp120 inhibits T cell activation by interfering with expression of costimulatory molecules CD40 ligand and CD80 (B71). J Immunol 1995;155:917-24.

57 Chehimi J, Starr SE, Frank I, et al. Impaired interleukin 12 production in human immunodeficiency virus- infected patients. J Exp Med 1994;179:1361-6.

58 Clerici M, Lucey DR, Berzofsky JA, et al. Restoration of HIV-specific cell-mediated immune responses by interleukin-12 in vitro. Science 1993;262:1721-4.

59 Wilson CC, Olson WC, Tuting T, Rinaldo CR, Lotze MT, Storkus WJ. HIV-1-specific CTL responses primed in vitro by blood-derived dendritic cells and Th1-biasing cytokines. J Immunol 1999;162:3070-8.

60 Belyakov IM, Ahlers JD, Brandwein BY, et al. The importance of local mucosal HIV-specific CD8(+) cytotoxic $\mathrm{T}$ lymphocytes for resistance to mucosal viral transmission in mice and enhancement of resistance by
local administration of IL-12. J Clin Invest 1998;102: local admin

61 Chougnet C, Thomas E, Landay AL, et al. CD40 ligand and IFN-gamma synergistically restore IL-12 production in HIV-infected patients. Eur J Immunol 1998;28:646-56.

62 Nakajima A, Kodama T, Morimoto S, et al. Antitumor effect of CD40 ligand: elicitation of local and systemic antitumor responses by IL-12 and B7. J Immunol 1998;161:1901-7.

63 Brunda MJ, Luistro L, Warrier RR, et al. Antitumor and antimetastatic activity of interleukin 12 against murine tumors. J Exp Med 1993;178:1223-30.

64 Coughlin CM, Salhany KE, Wysocka M, et al. Interleukin-12 and interleukin-18 synergistically induce 
murine tumor regression which involves inhibition of angiogenesis. J Clin Invest 1998;101:1441-52.

65 Bauer KS, Dixon SC, Figg WD. Inhibition of angiogenesis by thalidomide requires metabolic activation, which is 66 Kenyon BM, Browne F, D'Amato RJ. Effects of thalidomide and related metabolites in a mouse corneal model of neovascularization. Exp Eye Res 1997;64:971-8.

67 Joseph IB, Isaacs JT. Macrophage role in the anti-prostate cancer response to one class of antiangiogenic agents. Natl Cancer Inst 1998;90:1648-53.

68 D'Amato RJ, Loughnan MS, Flynn E, Folkman J. Thalidomide is an inhibitor of angiogenesis. Proc Natl Acad Sci USA 1994;91:4082-5.

69 Berenson JR, Bergsagel PL, Munshi N. Initiation and maintenance of multiple myeloma. Semin Hematol 1999;36:9-13.

70 Posavad CM, Koelle DM, Corey L. High frequency of CD8+ cytotoxic T-lymphocyte precursors specific for herCD8+ cytotoxic T-lymphocyte precursors specific for her-
pes simplex viruses in persons with genital herpes. J Virol pes simplex virus

71 Ferbas J. Perspectives on the role of CD8+ cell suppressor factors and cytotoxic T lymphocytes during HIV infection. AIDS Res Hum Retroviruses 1998;14 (suppl 2):S153-60.
72 Gollob JA, Schnipper CP, Orsini E, et al. Characterization of a novel subset of CD8 $(+) \mathrm{T}$ cells that expands in patients receiving interleukin-12. J Clin Invest 1998;102: $561-75$

73 Cavanagh LL, Barnetson RS, Basten A, Halliday GM. Dendritic epidermal T-cell involvement in induction of CD8+ T cell- mediated immunity against an ultraviolet radiationinduced skin tumor. Int J Cancer 1997;70:98-105.

74 Odeka EB, Miller V. Thalidomide in oral Crohn's disease refractory to conventional medical treatment. J Pediatr Gastroenterol Nutr 1997;25:250-1.

75 Waters MF, Laing AB, Ambikapathy A, Lennard-Jones JE. Treatment of ulcerative colitis with thalidomide. BMJ 1979;1:792.

76 Wettstein AR, Meagher AP. Thalidomide in Crohn's disease. Lancet 1997;350:1445-6.

77 Stack WA, Mann SD, Roy AJ, et al. Randomised controlled trial of CDP571 antibody to tumour necrosis factor-alpha in Crohn's disease. Lancet 1997;349:521-4.

78 Mayer L, Eisenhardt D. Lack of induction of suppressor T cells by intestinal epithelial cells from patients with inflamcells by intestinal epithelial cells from patients with inflam
matory bowel disease. J Clin Invest 1990;86:1255-60. 